Hispania Sacra, LXI

123, enero-junio 2009, 353-370, ISSN: 0018-215-X

\title{
EL OBISPO QUE ESTUVO A PUNTO DE SER PROCESADO. ANTONIO PALENZUELA Y LA «CÁRCEL CONCORDATARIA» DE ZAMORA
}

\author{
POR \\ Pablo Martín de Santa Olalla Saludes \\ Doctor en Historia Contemporánea. Universidad Autónoma de Madrid
}

\begin{abstract}
RESUMEN
El presente artículo se centra en uno de los conflictos menos conocidos de las relaciones Iglesia-Estado en el Posconcilio: el que podríamos llamar caso Palen$z$ zuela, un asunto de posible enjuiciamiento que nunca llegó a producirse por el devenir de la política española, que conllevó un cambio en el Gobierno (Carlos Arias Navarro en lugar del fallecido Almirante Carrero Blanco) en el que se apostó por una línea de diálogo abierto con la Santa Sede (rápidamente frustrada por hechos como el caso Añoveros) que, sin embargo, nunca llegó a obtener frutos de auténtica trascendencia.
\end{abstract}

PALABRAS ClAVE: Iglesia Católica, Estado español, enjuiciamiento, cambios gubernamentales

\section{THE BISHOP WHO WAS ON THE VERGE OF BEING PROCESSED. ANTONIO PALENZUELA AND «CONCORDATARIAN JAIL» OF ZAMORA}

\begin{abstract}
The present article is centred in one of the conflicts less known about relations Catholic Church-Spanish State after Council Vatican II: the one who could be called «case Palenzuela», a matter of possible indictment that never went so far as to take place because of the events in spanish politics (the change in Presidency of Government, when Carlos Arias Navarro relieved murdered Admiral Carrero Blanco), betting for a line of dialogue opened with the Holy See
\end{abstract}


(fastly frustrated by facts like «case Añoveros») that, in any case, never went so far as to obtain fruits of authentic trascendency.

KEY WORDS: Catholic Church, Spanish State, indictment, governmental changes

Recibido/Received 21-02-2008

Aceptado/Accepted 30-12-2008

El 12 de diciembre de 1973 la subsecretaría del ministerio de Justicia, José del Campo Llarena, enviaba a Laureano López Rodó, Ministro de Asuntos Exteriores, el Auto de la Sala Segunda del Tribunal Supremo, solicitando la autorización a la Santa Sede para que pudiera ser enjuiciado de posible conducta delictiva el entonces Obispo de Segovia, Antonio Palenzuela. Esta petición se realizaba por unas declaraciones que el prelado había efectuado un mes antes al diario El Norte de Castilla, con duras acusaciones por el trato que recibían en ese momento los clérigos presos en la llamada "cárcel concordataria», un edificio dedicado exclusivamente a sacerdotes y religiosos, anejo a la cárcel para presos comunes de Zamora, ubicada a las afueras de la ciudad.

Sin embargo, Antonio Palenzuela nunca llegó a ser juzgado por los supuestos delitos que se le imputaban: los acontecimientos políticos lo impidieron. En efecto, el 20 de diciembre de 1973 el Almirante Carrero Blanco era asesinado por la banda terrorista ETA y Franco decidió entonces nombrar en su lugar Carlos Arias Navarro hasta ese momento Ministro de la Gobernación. Así, Arias consideró necesario relevar en Asuntos Exteriores a Laureano López Rodó, colocando en su lugar a Pedro Cortina Mauri, Embajador en París y número uno del escalafón diplomático. Desconocemos si López Rodó, de haberse mantenido al frente del Palacio de Santa Cruz, hubiera seguido adelante con el procesamiento de Palenzuela, pero sí sabemos que Cortina decidió parar en seco todo el asunto ya que su prioridad era encauzar las relaciones con la Santa Sede para una posible renovación o actualización del Concordato de $1953^{1}$.

Lo que podríamos llamar el caso Palenzuela constituye una de las manifestaciones más claras del fuerte nivel de tensión que llegaron a alcanzar las relaciones entre Régimen de Franco y la Iglesia Católica española, que, debe recordarse, contaba con el apoyo claro y decidido de la Santa Sede en su proyecto de ser independiente. En ese sentido, aquellas declaraciones del entonces Obispo de Segovia se situaban dentro de una terrible panorámica general perfectamente descrita por quien en ese momento lideraba el catolicismo español, el Cardenal Vicente Enrique y Tarancón, y que puso al borde de la ruptura la relación

\footnotetext{
${ }^{1}$ La revisión del Concordato de 1953 en el marco del Posconcilio fue la cuestión en la que se centró mi tesis doctoral y se plasmó en la publicación del libro La Iglesia que se enfrentó a Franco. Pablo VI, la Conferencia Episcopal y el Concordato de 1953. Madrid, Dilex, 2005.

Hispania Sacra, LXI

123, enero-junio 2009, 353-370, ISSN: 0018-215-X
} 
entre Roma y el franquismo ${ }^{2}$. Un régimen al que daba el nombre una persona (el General Francisco Franco) que tan sólo veinte años antes había recibido la Orden Suprema de Cristo como reconocimiento a sus méritos por sus favores a la Iglesia española.

\section{ANTECEDENTES. LA «CÁRCEL CONCORDATARIA» DE ZAMORA}

El origen de la llamada «cárcel concordataria» de Zamora se halla en el Concordato firmado el 27 de agosto de 1953. En su artículo XVI estipulaba que, en caso de detención o arresto, los clérigos y los religiosos serían

«(...) tratados con las consideraciones debidas a su estado y a su grado jerárquico.

Las penas de privación de libertad serán cumplidas en una casa eclesiástica o religiosa que, a juicio del Ordinario del lugar y de la autoridad judicial del Estado, ofrezca las convenientes garantías; o, al menos, en locales distintos de los que se destinan a los seglares, a no ser que la autoridad eclesiástica competente hubiera reducido al condenado al estado laical» ${ }^{3}$.

El clima en que se creó este privilegio para clérigos era, sin embargo, bien distinto veinte años después. En 1953, cuando se acordó que los religiosos y sacerdotes cumplieran sus penas en establecimientos diferentes a los del resto de

2 «El Ministerio de la Gobernación, sirviéndose de la Dirección General de Seguridad, había organizado una ofensiva abierta contra los sacerdotes llamados progresistas. Era normal que miembros de la Policía o de la Guardia Civil vigilasen a estos sacerdotes, tomasen notas durante sus homilías y les molestasen a la menor ocasión. Estaban ayudados en esta ofensiva por los llamados Guerrilleros de Cristo Rey, dirigidos por Sánchez Covisa, que tenían bula para todo: irrumpían en las iglesias y armaban alborotos, de los cuales hacían responder, no pocas veces, a los mismos curas.

Multas exorbitantes (sin proporción a las que se imponían a otros estamentos sociales) que provocaban el encarcelamiento subsidiario porque no se pagaban (con el sarcasmo, algunas veces, de imponer las multas por deterioro del ministerio sacerdotal), erosionaban públicamente el prestigio de los sacerdotes».

Campañas de insultos contra esos sacerdotes y en más de una ocasión contra los «obispos rojos», contra el nuncio de Su Santidad, contra la Secretaría de Estado y hasta contra el mismo Papa, eran frecuentes en los medios gubernamentales de información, en revistas de ultra derecha y hasta en alguna revista eclesiástica, Iglesia-Mundo, sin que el Ministerio tomase ninguna medida: daba la impresión de que estaban alentadas por los mismos ministerios.

Agresiones a sacerdotes y ofensas públicas contra obispos (llamó mucho la atención nacional e internacionalmente, la manifestación custodiada por las fuerzas del orden público en la que se presentaron pancartas intolerables: «Tarancón al paredón, obispos rojos a la horca», etc.) eran toleradas y, al parecer, fomentadas por los mismos que tenían el deber de evitarlas». Vicente Enrique y Tarancón, Confesiones. Madrid, PPC, 1996, pp. 586 y 587.

${ }^{3}$ El texto del Concordato de 1953 se encuentra publicado, por ejemplo, en Carlos Corral Salvador y José Giménez Martínez Carvajal, Concordatos vigentes. Textos originales, traducciones e introducciones, Madrid, Fundación Universitaria Española, 1981, Vol. II, pp. 55-83. 
españoles, era, a sabiendas de que esos delitos generalmente tenían carácter aislado e iban contra las personas, la propiedad o las costumbres, implicando a un sacerdote concreto pero sin alterar el orden público. Por ello, el Estado no tenía mayor inconveniente en que las penas de privación de libertad fueran realizadas en casas eclesiásticas, permitiendo así a las personas de condición religiosa que su dignidad específica no se viera enturbiada por el régimen penal común.

El problema es que, fundamentalmente tras el Concilio Vaticano II (196265), habían comenzado a proliferar entre los clérigos los llamados delitos «de carácter socio-político», viendo la autoridad civil una clara conexión entre las actividades de estos religiosos y los atentados contra el orden público, al tiempo que se mostraba frecuentemente una rebeldía total contra lo que el Régimen de Franco como dictadura suponía.

Si la situación de estos sacerdotes y religiosos se había hecho especialmente compleja, no era sólo porque estuvieran luchando contra el poder político, sino porque precisamente por ello en las casas religiosas los condenados por diferentes razones estaban creando graves problemas intraeclesiales. En otras palabras, eran los propios obispos los primeros que no querían tenerles bajo su jurisdicción, y, además, la autoridad civil no tenía ninguna garantía de que estos religiosos no fueran a evadirse de los conventos o de crear desórdenes dentro de ellos.

Así se llegó al acuerdo entre la jerarquía católica y el Régimen de Franco de crear un centro penitenciario específico para sacerdotes, la «cárcel concordataria» de Zamora, con lo que se cumplía de manera expresa lo establecido en el Concordato: los clérigos y religiosos no cumplirían sus penas en los establecimientos penitenciarios normales.

Sin embargo, la Iglesia no tardó en darse cuenta de que esa estrategia de juntar a todos los elementos «díscolos» en un mismo centro no servía de nada, pues no hacía más que consolidar o reproducir el problema. La mayor parte de los «inquilinos» de la «cárcel concordataria» eran sacerdotes de las diócesis de Bilbao y San Sebastián, conocidos por su filiación tanto nacionalista y directamente, independentista. Entre ellos consolidaban su ideal político y de ninguna manera se acababan retractando de lo que les había llevado a la cárcel. Así que, a partir de los años 1968-69, los encargados de dirigir las diócesis de Bilbao y San Sebastián comenzaron a realizar movimientos para cambiar la situación. El objetivo era claro: la supresión de la «cárcel concordataria». No tenían tan clara la alternativa.

Las primeras gestiones se habían realizado en $1969^{4}$. A petición de tres sacerdotes de la diócesis de Bilbao, se había logrado que fueran enviados a una

\footnotetext{
4 Seguimos la extensa carta que los obispos Jacinto Argaya (San Sebastián), Antonio Añoveros (Bilbao), Antonio Palenzuela (Segovia) y José María Setién (Auxiliar de San Sebastián) dirigieron el 8 de noviembre de 1973 al clero implicado en la cuestión y que fue publicada, por ejemplo, en el Boletín Oficial del Obispado de Bilbao (en adelante BOOB), 274, diciembre de 1973, pp. 681-685.
} 
casa religiosa en Villagarcía de Campos, un pueblo vallisoletano muy cercano a la localidad de Medina de Rioseco y, por tanto, todavía más lejos de las Vascongadas que Zamora. El resto de reclusos que se encontraban en la «cárcel concordataria» habían declinado la posibilidad de que se hicieran gestiones a su favor, aunque los prelados habían logrado para ellos la instalación de una calefacción en alguna dependencia de la cárcel. Además, se les había dado facilidades para que cursar estudios universitarios.

Al año siguiente, en 1970, Jacinto Argaya realizó gestiones ante el Capitán General de la VI Región Militar para que el sacerdote Juan Echabe ${ }^{5}$ pudiera ir a un monasterio, tal como este lo había pedido antes. La evidente desconfianza, mostrada por el militar hacia esa solución, hizo que el obispo se ofreciera como garantía de que el sacerdote realmente cumpliera las normas disciplinarias fijadas para el tiempo de reclusión. Sin embargo, Argaya se había encontrado con un «no» por respuesta y en 1971 lo había vuelto a intentar, aunque en este caso la petición se extendía a otro sacerdote, Julián Calzada, y, por tanto, le apoyaba en la tarea el Administrador Apostólico de Bilbao, José María Cirarda, el superior de Calzada. No se dejó sin tocar ningún posible elemento de apoyo al traslado («ministro de jornada», Ministro de Justicia, Presidente del Tribunal Supremo, Capitán General de la VI Región Militar, diversas autoridades provinciales...), pero el resultado fue exactamente el mismo: es decir, ninguno.

Argaya no se había rendido y había buscado entonces alternativas para Echabe. Así, había pensado en la posibilidad de que el sacerdote fuera trasladado a Jumilla (Murcia), pero el Capitán General de la VI Región Militar volvió a negarse alegando «especial peligrosidad». El Obispo de San Sebastián pidió entonces amparo al Capitán General de Burgos, al Teniente General Presidente del Consejo Supremo de Justicia Militar y al Nuncio Apostólico, en un asunto que estaba comenzando a ser un tormento para el prelado.

Mientras el Obispo de San Sebastián se hartaba de recibir denegaciones, hasta nueve, el ya Obispo de Bilbao Antonio Añoveros decidió ir personalmente a Zamora para visitar a los sacerdotes Juan Echabe, Julián Calzada ${ }^{6}$ y Jesús Sánchez ${ }^{7}$, que habían requerido su presencia. Estos le hicieron tres peticiones: 1. que hubiera un indulto parcial para el también sacerdote Nicolás Tellería. Lo deseaban todos sus compañeros de cárcel por su edad, su delicado estado de salud y haber cumplido ya más de la mitad de la condena; 2 . que se trasladara a

5 Juan Echabe Garracelaya cumplía una condena de 50 años de reclusión mayor, que había sido reducida a 30 , por un delito de subversión social armada y terrorismo.

6 Julián Calzada Ugalde cumplía condena refundida de 22 años y un día por un delito de rebelión militar.

${ }^{7}$ No hemos encontrado datos sobre cuál era el tiempo de cárcel al que había sido condenado ni el motivo de dicha condena. 
una casa religiosa a Juan Echabe y Julián Calzada; y 3. que fuera a parar a una casa religiosa Jesús Sánchez, si era condenado en el juicio que tenía pendiente de celebración.

Añoveros acogió las peticiones y las trasladó al Ministro de Justicia, al Ministro del Ejército y al Capitán General de Burgos. Lo único que logró fue el traslado a una casa religiosa de Jesús Sánchez, quien, tras ser condenado, fue llevado al convento franciscano de Olite (Navarra).

La evidente falta de fuerza de los prelados de las diócesis vascas sobre las diversas autoridades políticas y militares llevó a Argaya y Añoveros a pedir amparo a la Conferencia Episcopal Española. El 20 de noviembre de 1972 una Comisión Especial integrada por el Vicepresidente de la Conferencia, José María Bueno Monreal, Cardenal-Arzobispo de Sevilla, y por los obispos de Bilbao, San Sebastián y Zamora, Ramón Buxarrais, visitó al Ministro de Justicia, Antonio María de Oriol y, estando presente el Director General de Asuntos Eclesiásticos, le formularon cuatro peticiones: a. que no desapareciera la prisión de Zamora para sacerdotes; b. que no se separara a los sacerdotes penados de los demás presos, ya que dicha separación constituiría, de hecho, una pena todavía más aflictiva que la que ya tenían; c. que los sacerdotes pudieran cumplir su condena en casas religiosas; y d. que el Gobierno tuviera alguna acción de benevolencia para con todos los presos.

La respuesta del ministro fue más bien parca y se limitó, en esencia, a señalar que el Gobierno no tenía mayor interés en conservar la «cárcel concordataria», y que el Concordato en ese momento vigente prohibía de manera tajante el que los clérigos pudiera estar en los mismos establecimientos que el resto de los presos.

Así se llegó a 1973, año donde todo se complicaría al máximo. En febrero, Antonio Añoveros volvió a escribir a Oriol y Urquijo para recordarle las peticiones formuladas, pero obtuvo el silencio por respuesta. Un mes después, Argaya y Añoveros volvieron a exponer ante la Comisión Permanente del Episcopado la situación de los sacerdotes presos en Zamora. En mayo Tarancón, Presidente de la Conferencia Episcopal, escuchó de «viva voz» los resultados de las gestiones cerca del ministerio de Justicia.

En junio de 1973 Luis Carrero Blanco se convierte en el primer Presidente del Gobierno nombrado por Franco. Aprovechando esta circunstancia, Antonio Añoveros fue a verle en julio. Fue ambicioso en sus peticiones: supresión de la «cárcel concordataria», traslado de los presos a casas religiosas e, incluso, un indulto general. Al tiempo que Añoveros hacía estas gestiones, Argaya aprovechaba para hablar con Oriol y Urquijo. El optimismo se apoderó de estos dos prelados y, sin saber qué iba a decidir el Gobierno al respecto, hicieron gestiones ante los superiores de diversos conventos, logrando la respuesta positiva de algunos de ellos, dispuestos a acoger a antiguos presos de Zamora. 
Siguiendo el orden cronológico, el 10 de agosto de 1973 Argaya, en representación de Añoveros y la suya propia, decidió visitar al «ministro de jornada», solicitándole un indulto para los sacerdotes con menor condena pendiente y, a su vez, la salida a una casa religiosa para los que la tenían mayor. Además, aprovechó para pedir una amnistía o una mayor aplicación del indulto para los reclusos que no eran sacerdotes. Nuevamente sin saber cuál era la respuesta del Gobierno, pero suponiendo que serviría para presionar, Argaya y Añoveros solicitaron a sus sacerdotes encarcelados en Zamora el consentimiento escrito para tramitar ante las autoridades del Estado su traslado a casas religiosas, contestando todos afirmativamente con la excepción de uno que los prelados no detallaban en su carta abierta de noviembre de 1973.

Tras más de tres años de gestiones, prácticamente nada había cambiado en la situación de la «cárcel concordataria» de Zamora. Los presos no colaboraban. Entre mayo de 1972 y septiembre de 1973, se habían negado a ver a sus propios obispos, hasta que el 12 de esa última fecha recibieron a Añoveros y Argaya. Al día siguiente, los dos obispos se reunieron en Loyola (Guipúzcoa), asistiendo los Vicarios Generales de la diócesis. Acordaron dirigir de nuevo sus peticiones por escrito al Presidente del Gobierno, al Ministro de Justicia y también al Ministro de Asuntos Exteriores. Insistieron el 19 de septiembre ante la Permanente de la Conferencia Episcopal, logrando su apoyo para un indulto general con motivo del Año Santo.

El 19 de octubre cayó el «jarro de agua fría». En el ministerio de Justicia no les recibió el Ministro, oficialmente «ausente», sino el Subsecretario, José del Campo Llarena. Dijo a los obispos que la situación no era tan «inhumana» como se trataba de hacer creer Ignorando sus dos visitas anteriores, les dijo que lo hicieran. Sólo obtuvieron la promesa de que el asunto sería tratado en el Consejo de Ministros.

Tras nuevas gestiones fracasadas ante el Capitán de la VI Región Militar, y ante la desconfianza que el asunto debía estar generando entre el clero de las diócesis de Bilbao y San Sebastián, Añoveros, Argaya y Setién y Antonio Palenzuela, obispo de Segovia, por estar un preso en Zamora Francisco García-Salve, el famoso «cura Paco», incardinado en su diócesis, decidieron explicar públicamente cuáles habían sido todas sus gestiones y expresar su deseo de que se acabara definitivamente con este centro y que la nueva situación en la que estos debieran cumplir sus penas se tomara de mutuo acuerdo entre la autoridad judicial del Estado y la autoridad eclesiástica. Era muy importante que la cárcel de Zamora desapareciera no sólo por ser perjudicial para los sacerdotes allí reclusos, sino también porque daba la impresión, explicaban los obispos, de que era la Iglesia la dotes.

«(...) responsable de la existencia de una cárcel del Estado, especial para los sacer- 
Finalmente no queremos ocultaros, queridos sacerdotes, el temor de que los sucesos que ahora nos ocupan, sean utilizados para fomentar divisiones y, aun en casos extremos, rupturas internas a la misma comunidad eclesial. Sacerdotes y Obispos, pueblo cristiano y Jerarquía, hemos de sentirnos miembros unidos de esa única Iglesia, a la que Cristo amó y, entregándose por Ella, la ganó con su propia sangre. Os invitamos, por ello, a contemplar una vez más, el momento que hoy vivimos en nuestras comunidades diocesanas, con el espíritu de fe y de caridad que nos unen en Jesucristo» ${ }^{8}$.

\section{Antonio PalenZuela. Un OBISPO INTELECTUAL AL SERVICIO DE LA IGLESIA}

Antes de entrar en el problema desencadenado por las declaraciones de Antonio Palenzuela, vamos a trazar un breve perfil sobre quién fue este prelado español. Nacido en la propia ciudad de Valladolid el 17 de enero de 1919, Palenzuela no se había formado en la archidiócesis castellano-leonesa, sino en la de Madrid-Alcalá, ordenándose el 26 de mayo de 1945. Madrid-Alcalá había sido cuna de un buen número de obispos crecidos a la sombra del llamado «Patriarca de las Indias», el vigués Leopoldo Eijo y Garay. Unos habían nacido en otras partes de España, como José María Bueno Monreal, aragonés, o de José María García Lahiguera, navarro, otros, en la misma provincia de Madrid, como Casimiro Morcillo, Jesús Enciso o Ricardo Blanco.

Palenzuela no puede considerarse un «protegido» de Eijo y Garay, ya que, cuando fue elevado al episcopado, el 11 de diciembre de 1969, el prelado vigués hacía ya más de un lustro que había fallecido. Palenzuela estaba en la corriente aperturista promovida por Pablo VI durante la gestión del Nuncio Dadaglio. Esos años fueron nombrados obispos Elías Yanes, Antonio Dorado Soto ${ }^{9}$, Javier Osés ${ }^{10}$ o José María Setién. Para ese momento, Palenzuela ya había publicado la que sería su principal contribución intelectual, el libro titulado Los sacramentos de la Iglesia ${ }^{11}$. Así, la Santa Sede decidió que Palenzuela pudiera volver como obispo a su Castilla y León natural, pero no para encabezar la archidiócesis de Valladolid, sino la vecina Segovia. Curiosamente, su predecesor, Daniel Llorente Federico, era también de Valladolid capital. Palenzuela no tardaría en mostrarse lejos del perfil típicamente nacionalcatólico, que caracterizó durante los veinticinco años de su predecesor. Como a la mayor parte de los obispos de aquel momento, el Concilio le había cogido a una edad muy avanza-

\footnotetext{
${ }^{8}$ Ibídem, p. 685.

${ }^{9}$ Cfr. P. Martín de Santa Olalla: «Un obispo para la Transición: Antonio Dorado Soto y la diócesis de Cádiz-Ceuta (1973-1981)», en A. Ramos SantanA, (Coord.): La Transición: política y sociedad en Andalucía. Cádiz, Ayuntamiento de Cádiz, 2005, pp. 241-255.

${ }^{10} \mathrm{Al}$ que quise biografiar en mi reciente contribución titulada Javier Osés. Un obispo en tiempos de cambio. Huesca, Instituto de Estudios Altoaragoneses, 2007.

11 Publicado en Madrid, Casa de la Biblia, 1965. 
da y con una formación teológica excesivamente tradicional ${ }^{12}$. Roma necesitaba «sabia nueva» para llevar a cabo el tan necesario «aggiornamento» de la Iglesia Católica que en España resultaba todavía más urgente.

Un «aggiornamento» que estaba resultando particularmente traumático en nuestro país, porque conllevó importantes tensiones de la jerarquía con los sacerdotes y con los seglares. Segovia no era una excepción. Con 350 sacerdotes atendían a los 175.000 habitantes, unos 500 de media por sacerdote ${ }^{13}$. Con todo se notaban ya problemas como la secularización del clero, el descenso de vocaciones, y la crisis desatada en el seno de la Acción Católica, cuando tomó Palenzuela posesión de la diócesis. Especialmente grave era el tema de los seglares. Como recuerda Enrique Berzal de la Rosa, a partir de 1968, año en culmina la crisis de la Acción Católica, sólo «(...) languidece un núcleo de hoacistas «abandonado» por los consiliarios y bastante remiso a los ánimos y ofrecimientos del obispo Palenzuela» ${ }^{14}$.

Palenzuela se alineó pronto con el sector aperturista del episcopado, cada vez con mayor fuerza dentro de la Conferencia Episcopal y liderado por el Arzobispo de Toledo y luego Cardenal, Vicente Enrique y Tarancón, que puso en graves aprietos al favorito del franquismo, el Arzobispo de Madrid-Alcalá Casimiro Morcillo, en las segundas elecciones para la presidencia de los obispos a comienzos de 1969.

Estaba poniéndose entonces en marcha una reunión conjunta de obispos y sacerdotes para buscar un acercamiento mutuo ante las evidentes tensiones dentro de la Iglesia española y ante el cada vez mayor auge de ese fenómeno que se conocería como contestación del clero. Ese experimento, liderado por Tarancón, para que tuviera éxito necesitaba encontrar recibir apoyos dentro del episcopado. Doce obispos formaron parte de los equipos encargados de elaborar las ponencias a discutir dentro de lo que se conocería como Asamblea Conjunta de Obispos y Sacerdotes, celebrada en Madrid en septiembre de 1971. Uno de ellos, Antonio Palenzuela, que estaba en la línea de Antonio Añoveros, Maximino Romero de Lema, Antonio Dorado Soto, Javier Osés o Elías Yanes ${ }^{15}$.

Sin embargo, Palenzuela se colocaría en el «punto de mira» del Régimen cuando en 1973 decidió acoger en la diócesis a un sacerdote encausado en el llamado Proceso 1001, Francisco García-Salve (lo que convirtió en lo que dentro del vocabulario eclesiástico se conoce como «obispo benévolo», es decir,

12 H. Raguer: Réquiem por la cristiandad. El Concilio Vaticano II y su impacto en España. Barcelona, Ediciones Península, 2006, p. 61.

${ }_{13}$ Datos en http://www.catholic-hierarchy.org/diocese/dsego.html.

14 E. Berzal De La Rosa: Sotanas rebeldes. Contribución cristiana a la transición democrática. Valladolid, Diputación Provincial de Valladolid, 2007, p. 52.

15 Véase al respecto ENRIQUE Y TARANCón, V., op. cit., p. 454. 
aquellos que aceptan a clérigos que no pueden seguir desarrollando su labor pastoral dentro de la diócesis a la que pertenecen, como era el caso de GarcíaSalve en Madrid). En ese sentido, la postura tomada por Palenzuela puede decirse que fue acogida de manera favorable dentro de la diócesis, ya que más de cien sacerdotes (en torno al 30\% del clero) decidieron hacer pública una carta donde agradecían «la postura humana y cristiana» del obispo vallisoletano ${ }^{16}$. Probablemente con este hecho las autoridades franquistas corroboraron lo que venían sospechando desde comienzos de 1971, y era que los a su juicio peligrosos «focos de influencia hoacista», si habían sido «promovidos por sectores del clero progresista» en la provincia de Segovia, era porque se sentían apoyados por el titular de la diócesis, es decir, Antonio Palenzuela ${ }^{17}$.

Todos estos hechos explican la reacción hostilidad de las autoridades franquistas ante las declaraciones de Palenzuela a El Norte de Castilla. Un obispo, bajo sospecha, pues nunca había dado señales de identificación con el Régimen, ponía en tela de juicio la dictadura y abogaba por los derechos de presos encarcelados por contestatarios y por su filiación con el nacionalismo vasco, en un momento en el que la banda terrorista ETA, había comenzado a asesinar en 1968. Palenzuela daba muestras de protagonismo político. Finalmente, un contexto general de falta de entendimiento entre un Régimen que quería mantener su unión y estrecha vinculación con la Iglesia, que, a su vez, buscaba una independencia cada vez mayor. Recordemos la renuncia a los cargos políticos expresada tan sólo unos meses antes en el documento La Iglesia y la Comunidad Política. Esa Iglesia no parecía querer mantener en vigor aquel Concordato firmado tan sólo dos décadas antes. Todo ello nos permitirá entender cómo fue posible que, en un Estado confesionalmente católico, un obispo de la Iglesia pudiera ser procesado por los tribunales civiles.

\section{UNAS DECLARACIONES DESENCADENANTES DE LA CRISIS}

Los sacerdotes reclusos en Zamora decidieron iniciar una huelga de hambre para destapar su situación. Estaban convencidos, tras el fracaso de las gestiones de sus obispos, que era la única opción que les quedaba para conseguir su traslado a casas religiosas. En la primera semana dejaron de ingerir alimentos. El asunto, que ya de por sí resultaba bastante escandaloso, tomó una magnitud muy importante, pues se produjeron varios incidentes que ponían de manifiesto contaban con el apoyo de, al menos, una parte del sector aperturista de la Iglesia.

\footnotetext{
${ }^{16}$ Así se recuerda en E. Berzal DE LA RosA, op. cit., p. 152.
}

${ }^{17}$ Ibídem, p. 159. 
En su estrategia hubo tres frentes. Los jesuitas de la universidad de Deusto se recluyeron en el centro. El clero de la diócesis de Bilbao se encerró en el edificio del obispado. Pero el más grave fue, ciertamente, el que tuvo lugar en la Nunciatura de Madrid, literalmente «tomada» por un centenar de personas. Eso era no sólo un grave escándalo, sino un incidente diplomático en toda regla por tratarse de una legación diplomática de la Santa Sede, con plena personalidad jurídica internacional reconocida ${ }^{18}$.

En este contexto se produjeron las declaraciones de Antonio Palenzuela en uno de los principales periódicos regionales de España (el vallisoletano El Norte de Castilla). En una entrevista hecha mientras se recuperaba de un accidente de coche, a su regreso de su última visita a Zamora, Palenzuela vertió las siguientes acusaciones:

«Yo no he estado en las celdas, pero sí puedo decir que encontré al padre García Salve en peores condiciones de salud que en otra visita anterior que le hice. Según él y su abogado, el señor Gil Robles, me han contado, falta espacio para una mínima actividad física, indispensable para la salud; convivencia forzosa en celdas comunes que no permiten el aislamiento que con frecuencia exige el espíritu, máxime en momentos de tribulación; falta de higiene suficiente, vigilancia innecesaria, vejatoria y hasta cruel, que interrumpe el sueño de los reclusos hasta ocho, diez y más veces cada noche; limitaciones inadmisibles a fuentes de lectura y conocimiento más dolorosas para quienes tienes una especial formación intelectual; abusos en la aplicación de medidas disciplinarias en celdas de castigo por motivos nimios, que son más bien pretextos o provocaciones determinantes de inevitables reacciones de rebeldía... Resumiendo, los sacerdotes recluidos en la prisión de Zamora están sometidos a un régimen de una especial dureza, que no estaría nunca justificado desde un punto de vista meramente humano.

(...) De hecho, por causas que psiquiatras y expertos podrían explicar e independientemente de las condiciones materiales, la cárcel destinada exclusivamente a sacerdotes resulta mucho más despiadada que la reclusión del condenado común. Es como añadir una pena más.

(...) Ante todo, queremos hacer constar que ninguno de los obispos de San Sebastián y Bilbao han concedido ni les ha sido solicitado su consentimiento a fin de que las penas de privación de libertad que en estos momentos están sufriendo los sacerdotes de estas diócesis se cumplan en la Prisión Provincial de Zamora. Tampoco el obispo de Segovia ha concedido su consentimiento para que el sacerdote de esta diócesis sea retenido en la misma prisión con ocasión del proceso que contra él está en curso»19.

Por si no fuera poco lo que podía desatarse a raíz de las declaraciones de este obispo, los presos contribuyeron a hacer mayor el escándalo cuando, en ese

\footnotetext{
18 Este incidente fue relatado con detalle por Laureano López Rodó en su libro Testimonio de una política de Estado, Planeta, Barcelona, 1987, pp. 66 y 67. También, Archivo del Ministerio de Asuntos Exteriores (en adelante $A M A E$ ) R19630 E2. Informe $\mathrm{n}^{\circ} 219$, sobre la reclusión de sacerdotes y seglares en la nunciatura, dirigido al Ministro de Asuntos Exteriores. Madrid, 16 de noviembre de 1973.

${ }^{19}$ El Norte de Castilla, 16 de noviembre de 1973.
} 
mismo mes de noviembre, decidieron amotinarse en la prisión. Según la versión dada en el diario Arriba, a las nueve de la mañana de aquel día, mientras uno de los presos intentaba encender la caldera para disfrutar de agua caliente, el resto de ellos aparentaba estar dormido. Media hora más tarde, el director del centro y el jefe de servicios fueron avisados de que los sacerdotes,

«(...) armados de banquetas de madera y distintos palos, estaban destrozando a toda velocidad y con peligrosa agresividad cristales, puertas y ventanas, así como enseres del local, provocando también el origen de dos focos de incendio, localizados en el mueble que servía de altar y en el dormitorio general, donde habían apilado varios colchones de goma-espuma. Media hora más tarde, el tumulto era sofocado por la intervención de los funcionarios penitenciarios que despejaron a los agresores retirándolos hasta la parte del patio sin ofrecer resistencia alguna» ${ }^{20}$.

La dimensión de este conflicto obligó a la mismísima Santa Sede, a través del Consejo para los Asuntos Públicos de la Iglesia, a tomar cartas en el asunto. En efecto, el 7 de diciembre de 1973, menos de dos semanas antes de ser asesinado Carrero Blanco, este Consejo escribía a la embajada de España ante la Santa Sede para comentarle la inoportunidad de la «subsistencia» de la «cárcel concordataria» en vista no sólo de los acontecimientos que acababan de producirse, sino también del negativo reflejo que ello estaba teniendo tanto para la autoridad civil como para la eclesiástica.

La diplomacia vaticana se mostraba comprensiva con el comportamiento de los clérigos allí presos y, sin negar el espíritu y la letra del Concordato de 1953, daba vía libre a la posibilidad de que los sacerdotes fueran transferidos a una cárcel común, siempre con el consentimiento previo del Ordinario correspondiente, algo que los presos de Zamora hacía tiempo que venían demandando ante la negativa a enviarlos a casas religiosas ${ }^{21}$.

Estaba ya en marcha la maquinaria judicial del Estado. Estaba redactado el auto para procesar a Palenzuela por sus declaraciones a El Norte de Castilla. En él se destacaba que el Obispo de Segovia había hecho saber a su entrevistador que él, aunque se había reunido con uno de los presos, Francisco García-Salve, no había

20 Arriba, 18 de noviembre de 1973.

21 «...este Consejo juzga que no se puede omitir una consideración acerca de las comprensibles dificultades de orden psicológico que pueden haber encontrado dichos sacerdotes», AMAE R19453 E2. Nota verbal $n^{\circ} 7210 / 73$ del Consejo para los Asuntos Públicos de la Iglesia a la Embajada de España ante la Santa Sede. Ciudad del Vaticano, 7 de diciembre de 1973. Como se ve, esta notificación se hacía de manera impersonal: en lugar de Agostino Casaroli al embajador ante la Santa Sede, cargo vacante por el fallecimiento de su titular, Juan Pablo de Lojendio, Marqués de Vellisca, como responsables respectivos del Consejo y de la Embajada, la nota iba de institución a institución.

Hispania Sacra, LXI

123, enero-junio 2009, 353-370, ISSN: 0018-215-X 
«(...) estado en las celdas, relatando a continuación lo que el propio Sr. García Salve y su abogado, Sr. Gil Robles, le han contado, manifestando al periodista unos conceptos que no conoce de ciencia propia, sino a través de referencias de terceras personas, y que por supuesto no ha comprobado, por lo tanto, utilizando la aludida fuente y sin comprobar previamente la veracidad o autenticidad de lo que más tarde expone, a lo largo de la entrevista vierte conceptos dirigidos, en tendenciosa crítica, contra los funcionarios de Prisiones y la Administración Penitenciaria de Zamora y consecuentemente, de la Dirección General de Instituciones Penitenciarias, organismo dependiente del Ministerio de Justicia; y otros directamente contra el Gobierno, al establecer y mantener la Prisión de Zamora con una parte, exclusivamente, dedicada a la prisión preventiva o al cumplimiento de las penas por sacerdotes condenados» 22 .

Según el auto, las palabras de Palenzuela resultaban especialmente graves pues vertían duras acusaciones contra las más altas instituciones del Estado, que, además, no eran ciertas. El Tribunal Supremo daba total crédito a la nota informativa que la Dirección General de Instituciones Penitenciarias había hecho pública precisamente el 16 de noviembre de 1973, el día en que se publicaron las declaraciones del Obispo. En ella se afirmaba tajantemente que los seis presos que habían protagonizado el motín en la cárcel de Zamora disfrutaban, entre otras cosas, del espacio físico destinado a treinta posibles presos, con lo cual resultaba evidente la comodidad en la que estaban viviendo ${ }^{23}$. Es más, la nota decía que

«(...) entre las facilidades de que venían disfrutando pueden citarse juntamente con la Capilla, una sala de lectura, un aparato de televisión, una biblioteca y un amplio patio en el que podían practicarse varios deportes, lo que desmiente las presuntas e insatisfechas necesidades culturales o de esparcimiento invocadas frecuentemente, todo lo cual lleva a la consideración de que se está en presencia de un premeditado montaje de artificio, enderezado a atraer y confundir a la opinión pública» 24 .

Así, ¿qué delitos podían imputarse a Palenzuela? El auto iba directamente el artículo 252 del Código Penal, que castigaba con pena de prisión mayor e inhabilitación absoluta a los que, con propósito de perjudicar el crédito o la autoridad del Estado, hubieran hecho circular noticias o rumores falsos, desfigurados o tendenciosos. También podía aplicársele, por ejemplo, el artículo 457, que castigaba a quienes imputaran faltas de moralidad cuyas consecuencias pudie-

22 AMAE R19453 E2. Carta sin número del Subsecretario de Justicia al Ministro de Asuntos Exteriores. Madrid, 12 de diciembre de 1973. En esta carta se adjuntaba el auto del Fiscal dirigido a la Sala Segunda del Tribunal Supremo, que tenía fecha 24 de noviembre de 1973.

${ }^{23}$ Dada la abismal diferencia entre la versión dada por Palenzuela (quien, a su vez, hablaba por lo que le había contado García-Salve) y entre la proporcionada por la Dirección General de Prisiones, quise contrastar estas informaciones con una entrevista a alguien que también estuvo preso en Zamora, sacerdote de la diócesis de Madrid-Alcalá Mariano Gamo Vid. apéndice.

24 Arriba, 18 de noviembre de 1973, ya citado. 
ran ser perjudiciales para la fama y crédito del agraviado, en este caso, los funcionarios de prisiones, o el 161, que castigaba a quien injuriara gravemente al Gobierno.

Una vez que se hubiera confirmado mediante declaración previa de Palenzuela y del entrevistador, un tal «Hervás» cuyo auténtico nombre se desconocía, la veracidad de las acusaciones vertidas, el Fiscal suplicaba a la Sala Segunda del Tribunal Supremo que formulara querella criminal y que solicitara de

\begin{abstract}
«(...) la Santa Sede la licencia necesaria para la citación, emplazamiento y en su caso procesamiento, del querellado, Excmo. y Rvdmo. Sr. D. Antonio Palenzuela Velázquez, Obispo de Segovia, tramitando dicha autorización a través de los Ministerios de Justicia y de Asuntos Exteriores, a los que deberá remitirse copia del Auto que se dicte y de este escrito de querella, absteniéndose de proceder en tanto en cuanto no se reciba la licencia solicitada.

Una vez recibida, en su caso, la licencia a que se refiere el párrafo anterior, debe la Sala acordar se proceda a la práctica de las diligencias interesadas y cualesquiera otras que de ellas se deriven y se dicte en su día Auto de procesamiento contra el querellado, decretando al mismo tiempo las medidas inherentes a la eficacia de tal resolución» 25 .
\end{abstract}

\title{
LA PARALIZACIÓN DE UN ENJUICIAMIENTO
}

Cuando todo parecía visto para el enjuiciamiento de Palenzuela, un terremoto político provocó su inmediata paralización. El 20 de diciembre de 1973 Luis Carrero Blanco era asesinado en un brutal atentado cometido en Madrid y con ello la política en España quedaba momentáneamente bloqueada, a la espera de un nuevo Presidente. Franco sorprendió a todos nombrando a quien precisamente era encargado de velar por la seguridad de Carrero Blanco, el Ministro de la Gobernación Carlos Arias Navarro. Arias decidió que Laureano López Rodó, hasta entonces titular de la cartera de Asuntos Exteriores, fuera reemplazado, como hemos apuntado ya, por el diplomático Pedro Cortina Mauri.

Así, una de las primeras decisiones que tomó Cortina fue precisamente la de paralizar el proceso. Eso no suponía que el asunto quedara definitivamente en el olvido. A la espera de lo que pudiera suceder, las diversas autoridades políticas fueron indagando el estado de la causa al iniciarse el mandato de Arias Navarro. El 4 de enero de 1974 José Luis Pardos, Encargado de Negocios en la embajada de España ante la Santa Sede, informaba a Gabriel Fernández de Valderrama, Subsecretario de Asuntos Exteriores (y luego precisamente Embajador cerca de la Santa Sede) sobre su el tema de un posible enjuiciamiento del Obispo de Segovia.

${ }^{25}$ AMAE R19453 E2. Carta sin número del Subsecretario de Justicia al Ministro de Asuntos Exteriores. Madrid, 12 de diciembre de 1973, ya citada.

Hispania Sacra, LXI

123, enero-junio 2009, 353-370, ISSN: 0018-215-X 
Pardos era muy claro desde el principio: tanto si la Santa Sede daba permiso para que Palenzuela compareciera ante los tribunales, como si no lo hacía, las consecuencias podían ser «muy peligrosas». Si no se daba el permiso y se filtraba a la prensa que esa solicitud había sido cursada, el principio de autoridad del Estado, del poder judicial y del mismo Concordato de 1953 podía quedar en entredicho. Si, por el contrario, la Santa Sede concedía el permiso, las reacciones de la opinión pública española ante el hecho de que un obispo pudiera ser procesado podían convertir a Palenzuela en la «bandera y el mártir en torno al cual se reúnan las fuerzas extra y contra el Régimen» 26 .

Con su habitual estilo humorístico calificó el asunto de ««hot-potato» peligrosísimo». Recordaba que podía producirse en España algo muy parecido al incidente que había protagonizado en Italia por el Obispo de Prato, Pietro Fiordelli, a finales de los años cincuenta. Proponía, por tanto, una estrategia basada en cinco puntos: 1. actuar igual que la Santa Sede y utilizando su misma técnica, en la medida que esta fuera posible; 2. llamar personalmente al Nuncio Dadaglio, indicándole y pidiéndole toda clase de explicaciones sobre la actuación del Vaticano en todo este asunto, más teniendo en cuenta la situación tan crítica por la que atravesaba España durante esos días, al mismo tiempo que se le hacía ver las «consecuencias» que podían derivarse de esa actitud; 3. mandar a la Secretaría de Estado una carta escrita por Cortina en la que, «con toda clase de interrogantes, ponderaciones y énfasis», se pudiera «dejar en nebulosa» la responsabilidad de la propia Santa Sede en el hecho de haber tenido que iniciarse una acción judicial contra la persona de Palenzuela; 4. hacer una declaración «cualquiera aparecida de modo semi-oficial», lo que no sería difícil de incluir en los órganos de información, una crónica o un suelto, donde se comentara algo relacionado con el tema, teniendo en cuenta que la abrogación del privilegio del Fuero gozaba de un importante consenso entre los diversos sectores de la población española; y 5. aprovechando su visita Cortina a Roma con motivo de la canonización de la Beata Teresa de Jesús Jornet, el 27 de enero, Cortina celebrara varias visitas a las más altas autoridades vaticanas, deslizando el tema, si bien la diplomacia española pensaba que el Vaticano estaba totalmente informado del posible procesamiento de Palenzuela a través del Nuncio Dadaglio. Con eso se tenía una buena baza para obligar la Santa Sede a buscar un entendimiento con Madrid.

Pardos deseaba que, con la llegada de un nuevo Gobierno, las relaciones con la Santa Sede pudieran volver a su cauce:

«Perdóname de nuevo estas líneas que a título personal te pongo. Bien sabéis que yo estoy aquí, a pesar de la temporada que llevamos desde que se marchó el pobre Juan Pa-

${ }^{26} A M A E$ R19453 E2. Carta ${ }^{\circ} 7$ del Consejero de la Embajada cerca de la Santa Sede al Subsecretario de Asuntos Exteriores. Roma, 4 de enero de 1974. 
blo, con la cabeza todavía en orden para cumplir vuestras instrucciones al pie de la letra, pero no quiero dejar de mandarte estas reflexiones y sobre todo decirte que sea cual sea la situación para la Iglesia en España, es necesario devolver la confianza y poder reinstaurar un régimen de diálogo entre esta Embajada y la Secretaría de Estado, que desgraciadamente por las últimas notas y contra-notas y por la ausencia de un Jefe de Misión desde hace tantos meses en esta Embajada, se ha ido deteriorando día a día» ${ }^{27}$.

Ni Antonio Palenzuela ni ningún otro obispo fue juzgado por escándalos parecidos. No lo fue Antonio Añoveros en febrero de 1974, ni Alberto Iniesta en marzo de 1975, ni José Antonio Infantes Florido en mayo también de 1975. Pedro Cortina consideró necesario empezar de «cero» y las relaciones con la Santa Sede serían encauzadas de una manera acertada en la medida que lo permitían evidentes limitaciones. El ministro sí utilizaría este asunto en las negociaciones para la renovación concordataria, recordando, en la llamada segunda «cumbre» de Madrid, diciembre de $1974^{28}$, que una llamada suya había evitado el juicio a Palenzuela cuando la solicitud de procesamiento se encontraba ya a las puertas del Vaticano ${ }^{29}$.

El ministro logró en julio de 1974 la redacción de un proyecto de Concordato que, sin embargo, nunca llegó a ser firmado, debido al incierto futuro del Régimen de Franco y, sobre todo, a la decidida oposición de la cúpula episcopal española, que, en una reunión celebrada con Pablo VI en octubre de 1974, «finiquitó» toda posibilidad de renovación del acuerdo ${ }^{30}$.

Antonio Palenzuela seguiría denunciado con voz firme la actitud del Régimen, como pone de manifiesto la tesis doctoral de Enrique Berzal de la Rosa. En efecto, un artículo suyo publicado en la revista Por favor, 21 de julio de 1975, fue secuestrado por las autoridades. En él afirmaba la necesidad de dialogar con el marxismo, mostraba su deseo de acabar con una Iglesia de la Cruza$d a$ que, a su juicio, todavía existía, afirmaba la existencia de una lucha de clases dentro de la sociedad española e, incluso, se preguntaba por la validez del socialismo a la hora de resolver los problemas sociales. Una actitud, en definitiva, beligerante con el Régimen que, según la documentación publicada por este

\footnotetext{
27 Ibídem.

28 Véase al respecto Pablo Martín DE SANTA Olalla, «La actualización del Concordato de 1953: la tercera cumbre entre el Gobierno de Franco y la Santa Sede (diciembre de 1974)», Estudios Eclesiásticos, 304, enero-marzo de 2003, pp. 127-160.

${ }^{29}$ AMAE R19452 E3. Dirección General de Política Exterior. Negociaciones para la actualización del Concordato. Acta de la segunda reunión en Madrid, pp. 19-21.

${ }^{30}$ El contenido de esta reunión puede consultarse en ENRIQUE Y TARANCÓN, V., op. cit., pp. 724 y ss. La veracidad de sus palabras pudimos comprobarla una vez que consultamos la carta que el embajador Fernández de Valderrama envió a Cortina tras producirse esta reunión. Véase al respecto Archivo de la Embajada de España cerca de la Santa Sede R237 bis. Carta «muy secreta» sin número del Embajador español cerca de la Santa Sede al Ministro de Asuntos Exteriores. Roma, 29 de octubre de 1974. 
historiador vallisoletano ${ }^{31}$, podía estar alentada por el propio Tarancón, quien le había animado a seguir luchando por los procesados en el sumario 1001: claro que, como decimos, se trataba sólo de sospechas del franquismo, porque Tarancón nada dice sobre este tema en sus Confesiones.

Debemos señalar, a modo de conclusión, que la carrera eclesiástica de Palenzuela se frenó en seco. No fue el único caso dentro del sector aperturista del episcopado: Javier Osés, por ejemplo, no saldría de Huesca, y Alberto Iniesta nunca pasaría de la condición de Obispo auxiliar de Madrid-Alcalá. Claro que Francisco Peralta (Vitoria) o Pablo Barrachina (Orihuela-Alicante), ambos pertenecientes al sector conservador del episcopado, tampoco saldrían de sus respectivas diócesis.

El 12 de mayo de 1995 sería aceptada su renuncia de Palenzuela: contaba poco más de setenta y seis años, y su salud se resentía hacía ya tiempo. El 8 de enero de 2003 falleció en Segovia ${ }^{32}$, poco antes de que se cumplieran tres décadas del intento de procesamiento contra él. La cárcel «concordataria» desapareció con la Transición a la democracia y los locales que albergaron a aquellos clérigos, considerados «subversivos» volvieron a ser parte de la «cárcel de Zamora».

\section{APÉNDiCE «EnTrevista a Don Mariano Gamo, Realizada el 6 de Marzo DE 2006»}

Aun con el problema de toda fuente oral, y es que no se trata realmente de una fuente primaria, sino de una de carácter secundario, dado el carácter selectivo de la memoria humana y dada la propensión de los protagonistas históricos a utilizar los testimonios para justificar sus propias actuaciones, hemos creído interesante adjuntar este testimonio para poder ofrecer una versión lo más completa posible.

Hay que decir, antes de nada, que Gamo no se encontraba en la cárcel de Zamora cuando se produjeron los hechos de noviembre de 1973. Su estancia en Zamora había tenido lugar entre el 19 de enero de 1970 y el 3 de octubre de 1971. No obstante, él siguió en contacto con varios de los presos de Zamora, entre ellos Juan Echabe, que sí estaba cuando se produjo la rebelión. Afirma no haber escuchado comentario alguno sobre especiales cambios en las condiciones de la cárcel.

Según Gamo, la vida en Zamora no era especialmente fácil, pero tampoco era tan dura como la describía Palenzuela. Entre las peores cosas que hubieron

\footnotetext{
${ }^{31}$ Véase al respecto E. BERZAL DE LA Rosa, op. cit., pp. 182 y 183.

${ }^{32}$ Quien escribe estas líneas quiso tener un breve recuerdo para el prelado por medio del artículo «En recuerdo de Antonio Palenzuela», publicado en El Adelantado de Segovia, 11 de enero de 2003.
} 
de vivir estaba el hecho de dormir todos juntos en una especie de nave de cuatro o cinco metros de alto donde no había ningún tipo de calefacción, lo que les obligaba a acostarse vestidos e incluso a dormir con pasamontañas para combatir el frío. Eran tan bajas las temperaturas por la noche que los grifos que tenían al lado de la cama, al tener pequeños escapes de agua, aparecían por la mañana con una especie de estalactitas colgando de ellos. Por otra parte, la comida era de bastante baja calidad, lo que los presos fueron capaces de suplir con los abultados, en cantidad y calidad, envíos de alimentos que, desde las Vascongadas, llegaban en solidaridad con los presos originarios de estas tierras.

Echando mano primero de la declaración de Palenzuela, Gamo, que afirma haber tenido gran amistad personal con Palenzuela, y, de hecho, fue a verle tan sólo dos semanas antes de que este muriera, dice que no era cierto que no hubiera especio para actividad física, aunque sí es verdad que no era excesivo. Respecto a la falta de higiene, reconoce que sólo disfrutaban de agua caliente para la ducha los sábados, si bien él dice que, en su vida normal, estaba acostumbrado a ducharse sólo dos veces a la semana, algo lógico en una persona que se había criado en un seminario con tantas penalidades como el del Madrid de la posguerra. Niega, por el contrario, que hubiera vigilancia innecesaria. No debió ser tan innecesaria cuando, justo después de salir Gamo de la cárcel, los presos tenían excavado un túnel al exterior que fue detectado a tiempo por los funcionarios de la cárcel. Ni lo era vejatoria y cruel; que les interrumpieran el sueño 8, 10 ó más veces, tampoco, como máximo dos, sobre la 1:00 y sobre las 4:00 a.m., porque pasaban la porra por los barrotes para asegurar que estos no hubieran sido serrados. Solían hacerlo con suavidad de tal manera que muchas veces no despertaban a nadie. No había acceso limitado a la lectura, pues durante el día podían leer todo lo que querían siempre que fueran cosas suyas. No había abuso en la aplicación de medidas disciplinarias, pues, como mucho, aguantaban algún que otro insulto. En ese sentido, y sin sostener que GarcíaSalve no era creíble, Gamo considera necesario resaltar el carácter exaltado y excesivamente protagonista del llamado «cura Paco».

Gamo, que estuvo también preso en la cárcel de Carabanchel, aunque los curas estaban ubicados en un pabellón aparte, no reconoce ese régimen penitenciario de «especial dureza» y corrobora la declaración de Instituciones Penitenciarias, si bien matizando que no había capilla en su época. Lo único que hacían era rezar juntos todos por la noche antes de dormir, entonando cánticos «gudaris»). Podían ver la televisión pero nunca ningún programa informativo. Había biblioteca pero sólo formada por libros traídos por los presos y admitidos por la dirección del centro. Se podía practicar deporte aunque de manera limitada, ya que el patio de unos veinte metros de largo por diez de ancho apenas ofrecía posibilidades para esa actividad. 